\title{
Discordance between Self-Report and Genetic Confirmation of Sickle Cell Disease Status in African-American Adults
}

\author{
Christopher J. Bean ${ }^{\mathrm{a}}$ W. Craig Hooper ${ }^{\mathrm{a}}$ Dorothy Ellingsen ${ }^{\mathrm{a}}$ \\ Michael R. DeBaun ${ }^{b}$ Jennifer Sonderman ${ }^{d}$ William J. Blot ${ }^{c, d}$ \\ ${ }^{a}$ Division of Blood Disorders, National Center on Birth Defects and Developmental Disabilities, Centers for Disease \\ Control and Prevention, Atlanta, Ga., ${ }^{b}$ Vanderbilt-Meharry-Matthew Walker Center of Excellence in Sickle Cell \\ Disease, and ' Division of Epidemiology, Department of Medicine, Vanderbilt University Medical Center, Nashville, \\ Tenn., and ${ }^{\mathrm{d} I n t e r n a t i o n a l ~ E p i d e m i o l o g y ~ I n s t i t u t e, ~ R o c k v i l l e, ~ M d ., ~ U S A ~}$
}

\section{Key Words \\ Genetic communication · Health literacy · Hemoglobin . \\ Self-report · Sickle cell disease}

\begin{abstract}
Background: Sickle cell disease (SCD) is an autosomal recessive genetic disorder, with persons heterozygous for the mutation said to have the sickle cell trait (SCT). Serious adverse effects are mainly limited to those with SCD, but the distinction between disease and trait is not always clear to the general population. We sought to determine the accuracy of self-reported SCD when compared to genetic confirmation. Methods: From stratified random samples of Southern Community Cohort Study participants, we sequenced the $\beta$ globin gene in 51 individuals reporting SCD and 75 individuals reporting no SCD. Results: The median age of the group selected was 53 years (range 40-69) with $29 \%$ male. Only $5.9 \%$ of the 51 individuals reporting SCD were confirmed by sequencing, with the remaining $62.7 \%$ having SCT, 5.9\% having hemoglobin C trait, and $25.5 \%$ having neither SCD nor trait. Sequencing results of the 75 individuals reporting no SCD by contrast were $100 \%$ concordant with self-report. Conclusions: Misreporting of SCD is common in an older
\end{abstract}

\section{KARGER}

E-Mail karger@karger.com

www.karger.com/phg adult population, with most persons reporting SCD in this study being carriers of the trait and a sizeable minority completely unaffected. The results from this pilot survey support the need for increased efforts to raise community awareness and knowledge of SCD.

(c) 2014 S. Karger AG, Basel

\section{Introduction}

Sickle cell disease (SCD), which affects as many as one in every 365 births among African Americans in the US [1], encompasses a group of related recessive blood disorders caused by mutations in the $\beta$-globin gene $(H B B)$ and is defined by the presence of at least one hemoglobin $\mathrm{S}(\mathrm{Hb} \mathrm{S})$ allele [2]. Homozygous Hb SS, referred to as sickle cell anemia, is the most common form of the disease; however, SCD can also result from coinheritance of $\mathrm{Hb} S$ with a second abnormal $\beta$-globin chain variant, such as a hemoglobin $\mathrm{C}(\mathrm{Hb} \mathrm{C})$ or $\beta$-thalassemia allele. Individuals with only a single abnormal $\beta$-globin allele do not have SCD themselves; however, they can have affected children, since they are carriers of the sickle cell trait (SCT). 
The high rates of morbidity and mortality associated with chronic anemia, vaso-occlusive events, and tissue damage resulting from obscured blood flow in SCD have a major impact on individuals and families with the disease and make it a significant public health concern [3-5]. In the US, approximately 83,000 adults and 30,000 children were hospitalized with an SCD discharge diagnosis in 2004 alone, generating estimated costs of almost USD 500 million [6]. In addition, as many as 3 million individuals in the US carry SCT, and although SCT is largely asymptomatic, it has been associated under certain conditions with an increased risk for serious adverse events, including sudden death during strenuous exercise, venous thromboembolism, and renal complications $[7,8]$. National data on the prevalence of SCD or SCT by age are not available, but SCD would be expected to be lower in adults over age 40 , due to decreased life expectancies.

In spite of the prevalence and serious burden of this genetic disorder, community knowledge regarding the inheritance pattern of SCD, knowledge of personal sickle cell status, and the health and reproductive implications of SCD and SCT remains inadequate [9]. There have been very few population-based studies to assess knowledge of SCD, and those studies in high-risk communities suggest little improvement in the past several decades $[9,10]$. To date, no studies on the general population have directly compared individuals' understanding of their own disease status with laboratory results. As an initial step in assessing the extent of SCD awareness among participants in a large cohort study assessing chronic disease risk factors in urban and rural areas of the southeastern US, we obtained and assayed stored DNA samples collected from persons reporting SCD status.

\section{Methods}

This research was conducted among a selected subset of participants in the Southern Community Cohort Study (SCCS), an ongoing prospective cohort study of nearly 86,000 adult residents in 12 states in the southeastern US $[11,12]$. For the SCCS, most participants (86\%) enrolled in-person during 2002-2009 at participating community health centers (CHCs), institutions which provide basic health and preventative services mainly to low-income and uninsured persons. The remaining $14 \%$ of the cohort was enrolled by responding to a mailed questionnaire sent to randomly selected residents of the same 12 states. SCCS eligibility requirements included being age 40-79 years, having the ability to speak English, and not being under treatment for cancer (with the exception of non-melanoma skin cancer) within the past 12 months. Approximately two-thirds of enrollees self-reported their race as Black or African American (hereafter African American). SCCS participants provided written informed consent, and the In- stitutional Review boards of Vanderbilt University Medical Center and Meharry Medical College approved all SCCS protocols.

At CHC enrollment, SCCS participants completed a computerassisted baseline survey administered by a trained study interviewer in-person, while the remaining participants mailed a completed version of the same questionnaire. The survey, available online at www.southerncommunitystudy.org, included the question: 'Has a doctor ever told you that you have, or have you ever been treated for, sickle cell disease?' Participants enrolling at CHCs were asked to provide a blood sample, or if declining, a mouth cell sample, while those enrolling through the mail were sent mouth rinse cell collection kits to be sent back by return mail. The blood specimens were shipped daily from the participating $\mathrm{CHCs}$ to the study laboratory at Vanderbilt University where they were processed immediately and separated into components for long-term storage. Similarly, the returned mouth rinses were processed upon receipt for long-term storage. Approximately $90 \%$ of participants enrolling at CHCs provided a biologic specimen [12].

As part of molecular substudies utilizing stored biologic specimens among stratified random samples of over 5,000 AfricanAmerican SCCS members to assess distributions of multiple genotypes, extracted DNA was retrieved for the 52 individuals with available material who responded that they had or had been treated for SCD. For the current study, DNA aliquots from these individuals along with a similar convenience sample comparison group of 76 African-American adults of similar age, gender, recruitment method, and source of DNA (blood vs. mouth cell) from these same biomarker studies who reported no SCD, were shipped, blinded to self-reported SCD status, to the Centers for Disease Control and Prevention for genotyping. Exon 1 of the $H B B$ gene was sequenced to detect the DNA variants that result in abnormal $\beta$-globin production. All samples were run on an ABI 3730 DNA Analyzer, and sequences were reviewed using Sequencing Analysis 5.2 (Applied Biosystems, Inc., Foster City, Calif., USA). Individuals with $\mathrm{Hb}$ SS or sickle-hemoglobin $\mathrm{C}$ disease (Hb SC) were classified as confirmed SCD, those with only one $\mathrm{Hb}$ S allele as SCT, those with only one $\mathrm{Hb} \mathrm{C}$ allele as $\mathrm{Hb} \mathrm{C}$ trait, and those with neither allele affected as typical (no abnormal $\beta$-chain variants detected). Differences in proportions were examined by contingency table analyses employing Fisher's exact test for significance.

\section{Results}

Insufficient sample material was available for genotyping for 2/128 participants, leaving 51 individuals reporting SCD and 75 individuals reporting no SCD available for comparison. The median age at cohort entry was 53 years ( $73 \%$ female and $27 \%$ male, range $40-69$ years) for those reporting SCD and 54 years (71\% female and $29 \%$ male, range 40-67 years) for those not reporting SCD. The genotypes matched the self-report status of all 75 participants who responded no SCD (table 1). In total, 10/75 (13.3\%) of those reporting no SCD were carriers for either SCT or Hb C trait, but the difference between women $(10 / 53 ; 19 \%)$ and men $(0 / 22 ; 0 \%)$ was marked (Fisher's 
Table 1. Distribution of $\beta$-globin sequence analysis results among 126 African-American adults according to self-report of SCD status

\begin{tabular}{llrll}
\hline SCD self-report & SCD $^{\mathrm{a}}$ & \multicolumn{1}{c}{ SCT } & Hb C trait & Typical $^{\mathrm{b}}$ \\
\hline No $(\mathrm{n}=75)$ & 0 & $9(12.0 \%)$ & $1(1.3 \%)$ & $65(86.7 \%)$ \\
Yes $(\mathrm{n}=51)$ & $3(5.9 \%)$ & $32(62.7 \%)$ & $3(5.9 \%)$ & $13(25.5 \%)$ \\
\hline
\end{tabular}

${ }^{a}$ Two individuals identified with $\mathrm{Hb}$ SS and 1 with $\mathrm{Hb}$ SC.

${ }^{\mathrm{b}}$ No abnormal $\beta$-globin DNA variants detected.

Table 2. Distribution of $\beta$-globin sequence analysis results among 51 African-American adults self-reporting SCD according to gender and education level status

\begin{tabular}{lllll}
\hline Gender and education & SCD $^{\mathrm{a}}$ & SCT & Hb C trait & Typical $^{\mathrm{b}}$ \\
\hline $\begin{array}{rllll}\text { Female } \\
\quad \leq \text { High school }(\mathrm{n}=24)\end{array}$ & $2(8.3 \%)$ & $14(58.3 \%)$ & $2(8.3 \%)$ & $6(25.0 \%)$ \\
$\quad>$ High school $(\mathrm{n}=13)$ & 0 & $11(84.6 \%)$ & 0 & $2(15.4 \%)$ \\
$\begin{array}{l}\text { Male } \\
\quad \text { High school }(\mathrm{n}=4)\end{array}$ & 0 & $1(25.0 \%)$ & 0 & $3(75.0 \%)$ \\
$\quad>$ High school $(\mathrm{n}=10)$ & $1(10.0 \%)$ & $6(60.0 \%)$ & $1(10.0 \%)$ & $2(20.0 \%)$ \\
\hline &
\end{tabular}

exact test; $\mathrm{p}=0.03$ ). The overall incidence of $12 \%$ SCT in participants that reported no SCD was somewhat higher than the expected 8\% among African Americans [13], but this difference was not statistically significant in this small sample size.

Among the 51 successfully genotyped participants who self-reported SCD, only 3 (5.9\%) were confirmed to have the disease, while $32(62.7 \%)$ had SCT, $3(5.9 \%)$ had $\mathrm{Hb} \mathrm{C}$ trait, and 13 (25.5\%) carried no abnormal alleles at all (table 1). Table 2 shows the genotyping results by sex and educational status for those self-reporting SCD, with higher percentages of completely unaffected individuals among men $(5 / 14 ; 35.7 \%)$ than women $(8 / 37 ; 21.6 \%)$ and those of lower $(9 / 28 ; 32.1 \%)$ than higher educational status $(4 / 23 ; 17.4 \%)$, although neither difference was statistically significant.

\section{Discussion}

Despite years of newborn screening successfully identifying individuals with SCD in the US, there remains widespread misunderstanding about the genetics of the disease in the general population. Studies surveying and evaluating community knowledge have consistently reported responders' difficulty distinguishing between disease and carrier status and lack of understanding of the pattern of inheritance suggesting little success in improving public health education since the 1970s $[9,10,14-$ 16]. Additionally, individuals frequently reported not knowing the SCT or $\mathrm{Hb}$ C trait status of themselves, their spouses or their children and did not understand the risks to future children [14, 17]. Possible misreporting among those participants that do report knowledge of personal trait status suggests that the community understanding of SCD may be even lower than estimated in these studies.

Misunderstandings and inadequate knowledge about SCD have also been reported among new parents, a group who may have had more recent exposure to and personal need for this information. In a recent survey restricted to postpartum African-American women, and the only other study to validate self-report with test results, $25 \%$ did not know and $4 \%$ incorrectly reported their own hemoglobinopathy status [18]. Similarly, a survey of parents of children with either SCD or SCT reported significant misunderstanding of how SCD is inherited, although the parents of children with the disease had significantly higher knowledge [19]. It may be telling that in this study, parents of children with SCD had received information about the disease from their pediatricians and from an SCD clinic, while the parents of children with SCT had received no formal education or counseling services [19].

Although SCCS participants were not asked to report SCT status, our results are consistent with the preponderance of evidence indicating a knowledge gap between self-awareness about SCD and SCT in the AfricanAmerican community and their actual SCD or trait status. Indeed, when self-report of status was compared with DNA sequencing results, we found that a majority of participants reporting disease were in fact carriers. Surprisingly, however, we also found that one-quarter of those who reported having SCD actually carried no disease alleles at all. We found no significant difference by gender or education level in those that misreported SCD status, at least in this small sample set. Instead, our results suggest a need for a much broader approach to increasing genetic health literacy in this community, since individuals of both sexes and of each education level incorrectly identified their trait carrier status or carrying no sickle alleles as SCD. In contrast, none of the individuals reporting no SCD had evidence of the disease, 
suggesting that misclassification in this direction is less common. The results of this pilot study highlight the need for improved education of adults about their status of SCD, SCT, and $\mathrm{Hb} \mathrm{C}$ trait in public health and primary care settings.

\section{Acknowledgements}

The authors would like to thank the Southern Community Cohort Study team and participants. The findings and conclusions in this report are those of the authors and do not necessarily represent the official position of the Centers for Disease Control and Prevention.

\section{References}

1 Hassell KL: Population estimates of sickle cell disease in the U.S. Am J Prev Med 2010; 38(suppl 4):S512-S521.

2 Bender MA, Hobbs W: Sickle cell disease; in Pagon RA, Bird TD, Dolan CR, Stephens K, Adam MP (eds): GeneReviews. Seattle, University of Washington, 1993-2003. http:// www.ncbi.nlm.nih.gov/books/NBK1377/.

3 Ashley-Koch A, Yang Q, Olney RS: Sickle hemoglobin (Hbs) allele and sickle cell disease: a HuGE review. Am J Epidemiol 2000;151: 839-845.

4 Creary M, Williamson D, Kulkarni R: Sickle cell disease: current activities, public health implications, and future directions. J Womens Health (Larchmt) 2007;16:575-582.

5 Yusuf HR, Lloyd-Puryear MA, Grant AM, Parker CS, Creary MS, Atrash HK: Sickle cell disease: the need for a public health agenda. Am J Prev Med 2011;41(6 suppl 4):S376S383.

6 Steiner CA, Miller JL: Sickle cell disease patients in U.S. Hospitals, 2004. Statistical brief \#21; in Healthcare Cost and Utilization Project (HCUP) Statistical Briefs. Rockville, Agency for Health Care Policy and Research (US), 2006. http://www.ncbi.nlm.nih.gov/ books/NBK63489/.
7 Grant AM, Parker CS, Jordan LB, Hulihan MM, Creary MS, Lloyd-Puryear MA, Goldsmith JC, Atrash HK: Public health implications of sickle cell trait: a report of the CDC meeting. Am J Prev Med 2011;41(6 suppl 4):S435-S439.

8 Key NS, Derebail VK: Sickle-cell trait: novel clinical significance. Hematology Am Soc Hematol Educ Program 2010;2010:418-422.

-9 Boyd JH, Watkins AR, Price CL, Fleming F, DeBaun MR: Inadequate community knowledge about sickle cell disease among AfricanAmerican women. J Natl Med Assoc 2005;97: 62-67.

10 Lane JC, Scott RB: Awareness of sickle cell anemia among negroes of Richmond, VA. Public Health Rep 1969;84:949-953.

11 Signorello LB, Hargreaves MK, Steinwandel MD, Zheng W, Cai Q, Schlundt DG, Buchowski MS, Arnold CW, McLaughlin JK, Blot WJ: Southern community cohort study: establishing a cohort to investigate health disparities. J Natl Med Assoc 2005;97:972-979.

12 Signorello LB, Hargreaves MK, Blot WJ: The Southern Community Cohort Study: investigating health disparities. J Health Care Poor Underserved 2010;21(suppl 1):26-37.

13 Centers for Disease Control and Prevention, Department of Health and Human Services: Sickle cell disease: data and statistics. 2013. http://www.cdc.gov/ncbddd/sicklecell/data. html.
14 Treadwell MJ, McClough L, Vichinsky E: Using qualitative and quantitative strategies to evaluate knowledge and perceptions about sickle cell disease and sickle cell trait. J Natl Med Assoc 2006;98:704-710.

15 Manley AF: Legislation and funding for sickle cell services, 1972-1982. Am J Pediatr Hematol Oncol 1984;6:67-71.

16 Young WI, Peters J, Houser HB, Jackson EB Jr: Awareness of sickle cell abnormalities. A medical and lay community problem. Ohio State Med J 1974;70:27-30.

17 Long KA, Thomas SB, Grubs RE, Gettig EA, Krishnamurti L: Attitudes and beliefs of African-Americans toward genetics, genetic testing, and sickle cell disease education and awareness. J Genet Couns 2011;20:572-592.

18 Kusyk D, Acharya K, Garvey K, Ross LF: A pilot study to evaluate awareness of and attitudes about prenatal and neonatal genetic testing in postpartum African American women. J Natl Med Assoc 2013;105:85-91.

19 Acharya K, Lang CW, Ross LF: A pilot study to explore knowledge, attitudes, and beliefs about sickle cell trait and disease. J Natl Med Assoc 2009;101:1163-1172. 